ABSTRACT: ${ }^{1} \mathrm{H}$ magnetic resonance spectroscopy (MRS) of the brain and ${ }^{31} \mathrm{P}$ MRS and saturation transfer of resting skeletal muscle were used to investigate intracellular metabolites and fluxes through the creatine kinase (CK) reaction in a patient with the syndrome of mitochondrial myopathy, encephalopathy, lactic acidosis, and strokelike episodes (MELAS). Acute cortical lesions were characterized by severely elevated lactate levels and reduced concentrations of $\mathrm{N}$-acetylaspartyl compounds, glutamate, and myo-inositol. Similar but less extreme alterations were also observed in gray matter regions that appeared normal on magnetic resonance images. Investigation of the gastrocnemius muscle at rest demonstrated a reduced phosphocreatine level, elevated concentrations of inorganic phosphate and free adenosine 5 '-diphosphate, and an abnormally low phosphorylation potential. Besides a moderately increased muscular phosphocreatine concentration, none of the metabolic disturbances detected on MRS improved with oral creatine supplementation. Forward and reverse fluxes through the CK reaction did not significantly change upon creatine treatment. Follow-up MRS investigations may thus provide objective markers of treatment response in vivo without the hazards or inconvenience of biopsy.

(C) 2002 Wiley Periodicals, Inc. Muscle Nerve 25: 593-600, 2002

\title{
APPLICATION OF NMR SPECTROSCOPY TO MONITORING MELAS TREATMENT: A CASE REPORT
}

\author{
HARALD E. MÖLLER, PhD, ${ }^{1,2,3}$ DIRK WIEDERMANN, PhD, ${ }^{1}$ \\ GERHARD KURLEMANN, MD, ${ }^{4}$ THORSTEN HILBICH, PhD, ${ }^{1}$ and \\ GERHARD SCHUIERER, MD ${ }^{2}$ \\ ${ }^{1}$ Institut für Physikalische Chemie, Universität Münster, Münster, Germany \\ ${ }^{2}$ Institut für Klinische Radiologie, Universität Münster, Münster, Germany \\ ${ }^{3}$ Max-Planck-Institut für Neuropsychologische Forschung, Leipzig, Germany \\ ${ }^{4}$ Klinik und Poliklinik für Kinderheilkunde, Univeristät Münster, Münster, Germany
}

Accepted 4 December 2001

A point mutation at base pair 3243 or 3271 of the mitochondrial transfer RNA (tRNA) ${ }^{\mathrm{Leu}(\mathrm{UUR})}$ gene is most frequently the underlying cause of the maternally inherited syndrome of mitochondrial myopathy, encephalopathy, lactic acidosis, and strokelike

\footnotetext{
Abbreviations: $\gamma$-ATP, $\gamma$-phosphate of ATP; Acq, acquisitions; ADP adenosine 5'-diphosphate; ATP, adenosine 5'-triphosphate; CK, creatine kinase; Cr, creatine; DANTE, delays alternating with nutations for tailored excitation; MELAS, mitochondrial myopathy, encephalopathy, lactic acidosis, and strokelike episodes; MRI, magnetic resonance imaging; MRS magnetic resonance spectroscopy; NAA, N-acetylaspartyl compounds $\mathrm{PCr}$, phosphocreatine; $\mathrm{P}_{\mathrm{i}}$, inorganic phosphate; $\mathrm{PP}$, phosphorylation potential; ST, saturation transfer; STEAM, stimulated echo acquisition mode; tCr, total creatine; TA, acquisition time; TE, echo time; TR, repetition time; tRNA, transfer RNA; VOI, volume of interest

Key words: ${ }^{1} \mathrm{H}$ magnetic resonance spectroscopy; ${ }^{31} \mathrm{P}$ magnetic resonance spectroscopy; creatine kinase; creatine supplementation; MELAS Correspondence to: H.E. Möller, Max Planck Institute of Cognitive Neuroscience, Stephanstraße 1a, D-04103 Leipzig, Germany; e-mail: moeller@cns.mpg.de

(C) 2002 Wiley Periodicals, Inc.

Published online 11 March 2002 in Wiley InterScience (www.interscience. wiley.com). DOI 10.1002/mus.10084
}

episodes (MELAS). ${ }^{29}$ Common biochemical defects observed at muscle biopsy are impaired complex I or IV activities or multiple defects of respiratory chaining enzymes. The disease is characterized clinically by strokelike episodes associated with cerebral infarctions on magnetic resonance imaging (MRI) of the head; seizures; hemiparesis; visual loss; and progressive dementia, headaches, vomiting, and muscle weakness accompanied by accumulation of lactate. It is assumed that the infarcts are nonvascular and are due to transient oxidative-phosphorylation dysfunction within the brain parenchyma. The clinical course is variable, with patients becoming progressively disabled in a stepwise fashion. Therapeutic drug trials aim at the improvement of aerobic energy production and prevention of acidosis-related damage. However, their effectiveness is difficult to assess in view of the diversity of clinical manifestations and the fluctuating nature of the clinical course.

Localized magnetic resonance spectroscopy 
(MRS) permits the noninvasive investigation of metabolic abnormalities in human tissues in vivo. In MELAS patients, previous proton MRS studies of the brain have demonstrated an elevation of the intracellular lactate level and a decreased concentration of $\mathrm{N}$-acetylaspartyl compounds (NAA; i.e., mostly $\mathrm{N}$ acetylaspartate with an additional contribution from $\mathrm{N}$-acetylaspartyl glutamate). ${ }^{4,7,9,10,22,25,35}$ Phosphorus MRS investigations of brain $^{3,12,19}$ and skeletal muscle $e^{1,19,26,31}$ have revealed a decreased concentration of phosphocreatine (PCr), whereas that of inorganic phosphate $\left(\mathrm{P}_{\mathrm{i}}\right)$ was elevated. Unlike muscle biopsy, MRS permits noninvasive monitoring of treatment and may be a potentially useful tool for assessing therapeutic efficacy. In patients with primary mitochondrial disorders, serial ${ }^{1} \mathrm{H}$ MRS examinations have demonstrated a decline of intracerebral lactate levels during treatment with sodium dichloroacetate. ${ }^{11,21,25}$ Using skeletal muscle ${ }^{31} \mathrm{P}$ MRS, evidence for improved cellular energy state has been obtained in a MELAS patient following administration of riboflavin and nicotinamide. ${ }^{26}$

Recently, Hagenfeld et al. ${ }^{16}$ reported reduced frequency and intensity of headaches and improvement of work performance in a MELAS patient during creatine $(\mathrm{Cr})$ treatment. In normal subjects, it is well established that high-dose $\mathrm{Cr}$ intake for several days may elevate skeletal muscle $\mathrm{Cr}$ and $\mathrm{PCr}$ levels ${ }^{18}$ and improve performance during high-intensity, intermittent exercise. ${ }^{15}$ This beneficial effect was postulated to be due to higher pre-exercise $\mathrm{PCr}$ stores and an improved PCr resynthesis capacity. ${ }^{15}$ To study the physiological mechanisms underlying potentially beneficial effects of oral $\mathrm{Cr}$ supplementation, we used ${ }^{31} \mathrm{P}$ MRS for monitoring the therapeutic response in a girl with MELAS. Resting muscle intracellular phosphates and fluxes through the creatine-kinase (CK) reaction were repeatedly investigated by static spectroscopy and saturation-transfer (ST) measurements. In parallel, additional ${ }^{1} \mathrm{H}$ spectra of the brain were recorded before and 9 weeks after initiation of $\mathrm{Cr}$ treatment.

\section{MATERIALS AND METHODS}

Case Report. Our patient is a 14-year-old girl, the third child of nonrelated parents. Her siblings are healthy. Pregnancy and birth were uneventful, and the milestones of development were reached within the normal range. At the age of 9 years, epilepsia partialis continua with continuous twitches of the right face, arm, and leg occurred, accompanied by severe headache and "eye blinking" of the left eye. "Eye blinking" was the description given by the patient with reference to continuous visual flashes of lightning. The girl was functionally blind in her left eye. Electroencephalography showed continuous spikes in the left precentral and occipital region. Although resistant to all medical therapeutic trials with conventional antiepileptic drugs, the seizures stopped spontaneously after some days. They were followed by a Todd's paresis that lasted for several days. Lactate level was elevated in the cerebrospinal fluid and plasma. A point mutation at base pair 3243 of the mitochondrial tRNA ${ }^{\mathrm{Leu}(\mathrm{UUR})}$ indicated MELAS syndrome. Therapeutic trials were started with thiamine, riboflavine, coenzyme $Q_{10}$, and carnitine. Finally, $\mathrm{Cr}$ monohydrate at a dose of $5 \mathrm{~g}$ /day (body weight, $24 \mathrm{~kg}$ ) was introduced for 10 weeks. All treatments were tolerated well, but none was successful in eliminating plasma lactate or seizure activity. The epileptic syndrome was resistant to all antiepileptic drugs. The patient is now receiving lamotrigine and phenobarbital, with blood levels in the therapeutic range. She is unable to walk alone, is blind, and has developed sensorineural hearing loss. She has to be tube-fed.

Magnetic Resonance Imaging. All MRI examinations were performed at $1.5 \mathrm{~T}$ (Magnetom 63SP; Siemens, Erlangen, Germany). The study was conducted according to the Declaration of Helsinki after informed written consent had been obtained. Conventional spin-echo sequences were employed for MRI. An axial double-echo proton-density and T2-weighted sequence (repetition time, TR $2700 \mathrm{~ms}$; echo times, TE 15/90 ms; acquisitions, Acq 1; matrix $192 \times 256$; acquisition time, TA 8:42 min) and a coronal T1-weighted sequence (TR/TE $450 / 15 \mathrm{~ms}$; Acq 2; matrix $256 \times 256$; TA 3:55 min) were performed. The field of view was $230 \mathrm{~mm}$.

The first MRI study, which was performed before Cr treatment, showed multiple, mainly cortical, defects located in the cerebellar vermis, the right cerebellar hemisphere, the right occipital lobe, and the right parietal lobe. Furthermore, symmetric defects of the pallidum were found. The T2-weighted images showed edematous swelling of the cortex and mainly subcortical white matter of the right parietooccipital operculum extending into the dorsal parietal cortex and of the left parietal operculum. These lesions showed only mild signal loss on T1-weighted images resulting in a pseudothickening of the cortex. The follow-study after 9 weeks of Cr treatment showed the same defects without any changes (Fig. $1)$. The opercular lesion on the left had resolved without any definite defect, the right opercular lesion resulted in small bright area on T2-weighted images, possibly resembling a gliotic defect smaller 


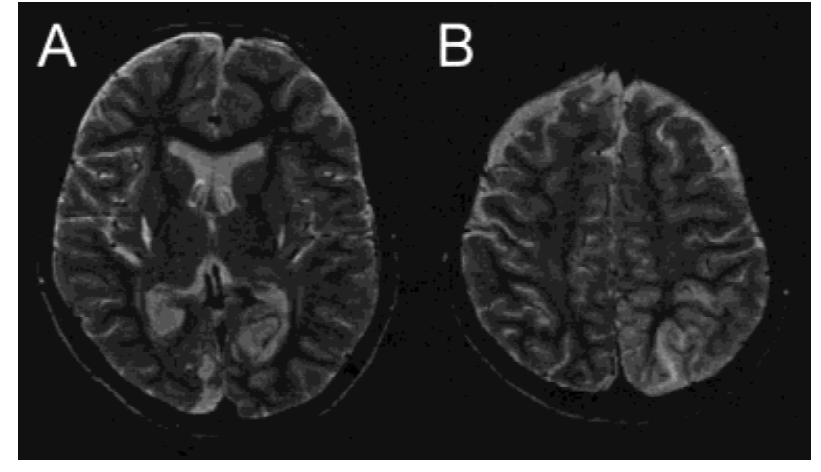

FIGURE 1. Axial T2-weighted spin-echo images (TR/TE 2700/90 $\mathrm{ms}$; slice thickness, $6 \mathrm{~mm}$ ) obtained during $\mathrm{Cr}$ treatment (second MRI examination). (A) Image from the level of the basal ganglia showing the symmetric pallidal and the right occipital defects as well as the acute cortical lesion of the left occipital lobe. Note the high intensity of the optic radiation, possibly resembling gliotic changes. (B) Slice, located $3 \mathrm{~cm}$ more cranially, demonstrating cortical swelling within the left parietal and paramedian cortex as well as localized subcortical edema.

than the original lesion. However, a new left occipital lesion including the left calcarine fissure and extending into the parietal and paramedian cortex had evolved. The MRI changes of the new lesion resembled the acute opercular lesions of the first study. Pseudoterritorial lesions resulting only partially in defects on follow-up studies are common and quite typical in patients with MELAS. The symmetric defects of the basal ganglia resemble those seen after cerebral anoxia and may be considered evidence of a previous episode of a more global cerebral energy crisis in this patient.

${ }^{1} \mathbf{H}$ Spectroscopy. Proton spectra were recorded with the standard imaging head coil immediately following the MRI examinations. Two 8-ml volumes of interest (VOI) with predominantly gray matter, one centered in the right opercular cortex and the other midline in the occipital cortex (Fig. 2) were repeatedly investigated 4 days before initiating Cr treatment and 9 weeks thereafter. All spectra were recorded applying the STEAM (stimulated echo acquisition mode $)^{13}$ technique (TR/TE 3000/20 ms; 1-K complex data points, Acq 128).

${ }^{31} \mathbf{P}$ Spectroscopy. An 80-mm diameter surface coil was employed for ${ }^{31} \mathrm{P}$ MRS studies. A baseline examination was performed immediately before initiation of $\mathrm{Cr}$ treatment ( 4 days after the first ${ }^{1} \mathrm{H}$ MRS study) and a second one after 10 weeks (9 days after the second ${ }^{1} \mathrm{H}$ MRS study) on the last day of Cr treatment. Spectra were recorded mainly from the gastrocnemius muscle with a pulse-and-acquire tech-
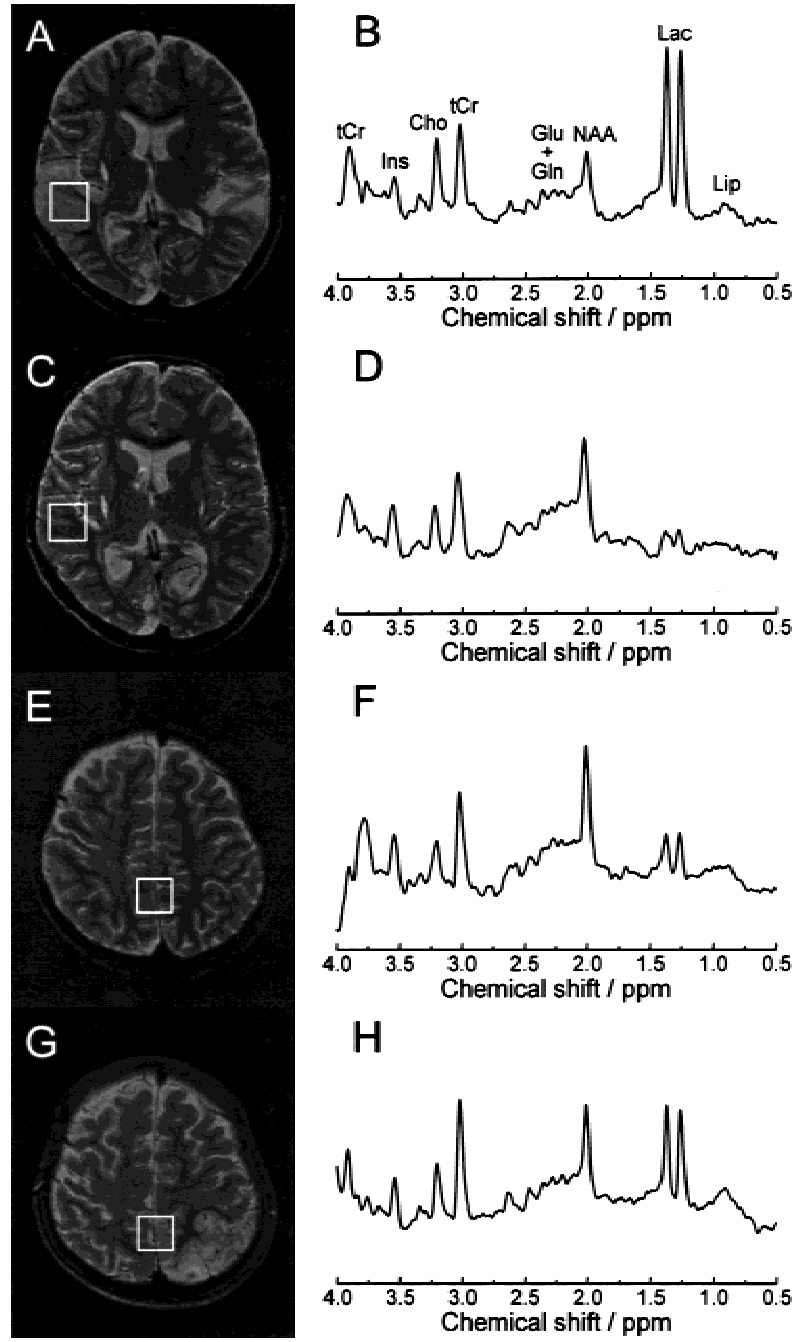

D
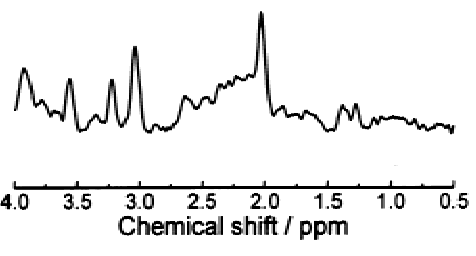

$\mathrm{F}$

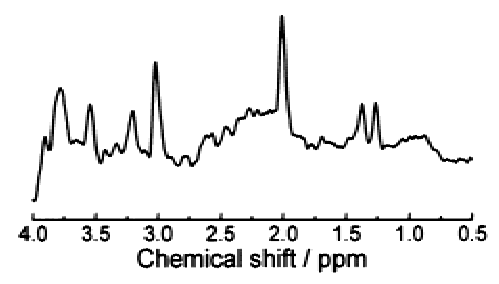

$\mathrm{H}$

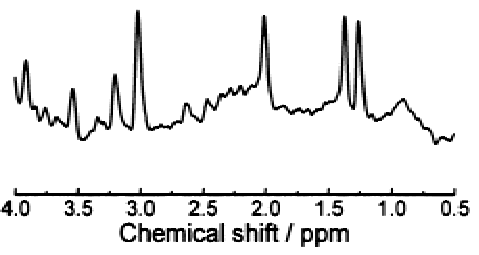

FIGURE 2. T2-weighted images and results obtained with ${ }^{1} \mathrm{H}$ MRS (TR/TE 3000/20 ms; Acq 128). Boxes indicate VOls selected for spectroscopy. The spectra show metabolite resonances from mobile lipids (Lip), lactate (Lac), NAA, glutamate (Glu), glutamine (Gln), tCr, choline compounds (Cho), and myoinositol (Ins). Brain MRI and MRS changes in the right parietooccipital operculum: (A) strokelike lesion with abnormal T2 prolongation (pretreatment), which appears mostly normal (C) after 9 weeks (during $\mathrm{Cr}$ treatment) and corresponding spectra from the VOI recorded (B) before and (D) during $\mathrm{Cr}$ treatment. Changes at $\mathrm{MRI}$ and $\mathrm{MRS}$ in the occipital region: (E) normal-appearing gray matter (pretreatment) and (G) acute strokelike lesion in the left occipital cortex (during $\mathrm{Cr}$ treatment) and corresponding ${ }^{1} \mathrm{H}$ spectra from the midline VOI obtained $(\mathbf{F})$ before and $(\mathrm{H})$ during $\mathrm{Cr}$ treatment.

nique (average flip angle $50^{\circ}$, TR $5 \mathrm{~s}, 1-\mathrm{K}$ complex data points, Acq 32). An initial static spectrum served for measuring steady-state peak areas and positions. For kinetic measurements, selective saturation of the resonance of either PCr or the $\gamma$-phosphate of adenosine 5 -triphosphate $(\gamma$-ATP) was achieved by a DANTE (delays alternating with nuta- 
tions for tailored excitation) ${ }^{24}$ pulse train (25 hard pulses of $200-\mu$ s duration, 2-ms interpulse delay). Each of these ST series consisted of nine spectra with different intervals $\tau$ (mixing time) between the DANTE and the readout pulse $(27 \mathrm{~ms}<\tau<4025$ $\mathrm{ms})$. Finally, a single spectrum was recorded $(\tau=27$ $\mathrm{ms}$ ) after shifting the frequency of the DANTE saturation scheme "to the left" of the $\mathrm{PCr}$ resonance by an increment equivalent of the separation of the PCr and $\gamma$-ATP peaks $(\Delta v=+62 \mathrm{~Hz}$; "mirror irradiation") for evaluation of radiofrequency spillover effects.

Data Analysis. Automated quantification of the ${ }^{1} \mathrm{H}$ MRS data to obtain absolute metabolite concentrations was performed by $\mathrm{LCModel}^{27}$ using a data base of calibrated model spectra. Previously recorded ${ }^{1} \mathrm{H}$ spectra (unpublished data) of normal cortical gray matter from six children (mean age, 14.3 years; range, 10-17 years) served as a basis for comparison.

Processing of the ${ }^{31} \mathrm{P}$ data included zero-filling to $2 \mathrm{~K}$, exponential multiplication $(5-\mathrm{Hz}$ line broadening), Fourier transformation, and Lorentzian line fitting $^{23}$ to determine resonance positions and areas. The $\mathrm{pH}$ was calculated from the chemical-shift difference between $\mathrm{P}_{\mathrm{i}}$ and $\mathrm{PCr},{ }^{32}$ and the intracellular free $\mathrm{Mg}^{2+}$ concentration, $\left[\mathrm{Mg}^{2+}\right]$, was computed using the chemical shifts of the $\alpha$ - and $\beta$-phosphate of ATP $\left(\alpha\right.$-ATP, $\beta$-ATP) ${ }^{36}$ To obtain concentration estimates, the peak area of the $\beta$-ATP resonance was used as a reference and assumed to represent a cytosolic ATP level of $8.2 \mathrm{mmol} / \mathrm{L} .{ }^{17}$ Functional mitochondrial status was assessed from the concentration of cytosolic free adenosine $5^{\prime}$-diphosphate (ADP), the phosphorylation potential (PP), defined as $[\mathrm{ATP}] /\left([\mathrm{ADP}] \times\left[\mathrm{P}_{\mathrm{i}}\right]\right)$, and the ratio of the mitochondrial ATP synthesis rate over its maximum value according to $\mathrm{V} / \mathrm{V}_{\max }=1 /\left\{1+\left(0.53 \times[\mathrm{PCr}] /\left[\mathrm{P}_{\mathrm{i}}\right]\right)\right\}^{8}$ In skeletal muscle, ADP is micromolar and, hence, below the sensitivity of in vivo ${ }^{31} \mathrm{P}$ MRS. Therefore, $\mathrm{ADP}$ levels and $\mathrm{V} / \mathrm{V}_{\text {max }}$ were computed from the CK reaction:

$$
\mathrm{PCr}^{2-}+\mathrm{MgADP}^{-}+\mathrm{H}^{+} \underset{\mathrm{k}_{\text {rev }}}{\stackrel{\mathrm{k}_{\text {for }}}{\rightleftarrows}} \mathrm{Cr}+\mathrm{MgATP}^{2-},
$$

by exploiting the metabolite ratio $\mathrm{P}_{\mathrm{i}} / \mathrm{PCr}$ as advocated by Chance et al. ${ }^{8}$ For comparison, reference ${ }^{31} \mathrm{P}$ spectra of the resting calf muscle were taken from a previous study (unpublished data) in nine healthy volunteers (mean age, 26.8 years; range, 2133 years).

A detailed description of the ST technique and its underlying theory, including a thorough analysis of the experimental limitations, is presented in a separate publication. ${ }^{34}$ Briefly, pseudo-first-order rate constants for the exchange of phosphate between ATP and PCr through the CK reaction, can be defined as $\mathrm{k}_{+1}=\mathrm{k}_{\text {for }} \times[\mathrm{ADP}] \times\left[\mathrm{H}^{+}\right]$and $\mathrm{k}_{-1}=\mathrm{k}_{\text {rev }} \times$ $[\mathrm{Cr}]$. The corresponding fluxes are therefore given by $\mathrm{v}_{\text {for }}=\mathrm{k}_{+1} \times[\mathrm{PCr}]$ and $\mathrm{v}_{\mathrm{rev}}=\mathrm{k}_{-1} \times[\mathrm{ATP}]$. The time-dependent behavior of the PCr and the $\gamma$-ATP signals during the ST experiment are dependent on $\mathrm{k}_{+1}$ and $\mathrm{k}_{-1}$. Hence, the pseudo-first-order rate constants are obtained by plotting the peak areas of both resonances as a function of the mixing time for both ST experiments (i.e., the one in which the PCr signal is saturated and another in which $\gamma$-ATP is saturated) and simultaneous fitting of all four time courses using nonlinear least-squares regression. Reference data for the normal resting calf muscle were acquired in three healthy volunteers (mean age, 31.3 years; range, 31-32 years).

Differences between patient and control data were regarded as significant on the $1 \%, 0.01 \%$, or $0.0001 \%$ level if they exceeded $2.5 \times, 4 \times$, or $5 \times$ the standard deviation (SD) in the control group.

\section{RESULTS}

'H Spectroscopy. Figure 2 shows brain spectra from repeated investigations of the two VOIs. A doublet signal (splitting of $7 \mathrm{~Hz}$ ) from intracerebral lactate at $1.33 \mathrm{ppm}$, which is not readily detected by ${ }^{1} \mathrm{H}$ MRS at $1.5 \mathrm{~T}$ in normal brain, was clearly visible in all patient spectra. Metabolite concentrations are summarized in Table 1. Before Cr treatment, an acute strokelike lesion was found in the right parietooccipital operculum (Fig. 2A). The spectrum from this area (Fig. 2B) indicates an extreme elevation of lactate and reduced NAA ( $31 \%$ of the mean control value). In addition, glutamate and myo-inositol were reduced, whereas the levels of other metabolites, such as glutamine, total creatine (tCr, i.e., Cr plus $\mathrm{PCr}$ ), and choline compounds, were normal. After 9 weeks, the lesion had almost resolved (Fig. 2C). In the corresponding spectrum (Fig. 2D), the area of the lactate signal was markedly reduced (22\% of the value of the first examination), though it was still abnormal. Additionally, NAA partly recovered (to $53 \%$ of normal) but still remained below control levels. Similar findings, that is, elevated lactate and decreased NAA (55\% of the mean control value) plus reduced glutamate and myo-inositol, were observed in a ${ }^{1} \mathrm{H}$ spectrum (Fig. 2F) acquired midline in the occipital cortex. Note that this location appeared normal at the first MRI examination (Fig. 2E), whereas a strokelike episode occurred during $\mathrm{Cr}$ treatment (Fig. 2G). The corresponding ${ }^{1} \mathrm{H}$ spec- 
Table 1. Cytosolic metabolite concentrations (in mmol/L) obtained from cortical gray matter with ${ }^{1} \mathrm{H}$ MRS.

\begin{tabular}{|c|c|c|c|c|c|}
\hline \multirow[b]{3}{*}{ Metabolite } & \multirow{3}{*}{$\begin{array}{c}\text { Control data } \\
\quad(n=6)\end{array}$} & \multicolumn{4}{|c|}{ MELAS } \\
\hline & & \multicolumn{2}{|c|}{ Parieto-occipital operculum } & \multicolumn{2}{|c|}{ Occipital cortex } \\
\hline & & Baseline & On treatment & Baseline & On treatment \\
\hline Lactate & $<1.0$ & $14.1^{\star}$ & $3.1^{\dagger}$ & $5.0^{*}$ & $10.5^{\star}$ \\
\hline NAA & $11.8 \pm 1.4$ & $3.6^{*}$ & $6.3^{\ddagger}$ & $6.5^{\ddagger}$ & $5.8^{\dagger}$ \\
\hline Glutamate & $11.0 \pm 2.3$ & $4.4^{\ddagger}$ & 7.4 & $3.9^{\ddagger}$ & 6.7 \\
\hline Glutamine & $4.9 \pm 1.2$ & 6.0 & 4.6 & 5.7 & 5.0 \\
\hline $\mathrm{tCr}$ & $6.9 \pm 0.9$ & 4.8 & 6.5 & 6.0 & 6.8 \\
\hline Choline & $1.1 \pm 0.1$ & 1.4 & 1.2 & 1.3 & 1.2 \\
\hline Myo-inositol & $5.6 \pm 0.3$ & $2.6^{*}$ & 5.4 & $3.6^{*}$ & $3.2^{*}$ \\
\hline
\end{tabular}

${ }^{*}$ Beyond \pm 5 SDs (i.e., $\mathrm{P}<.000001$ ) of the mean value in controls.

${ }^{+}$Beyond \pm 4 SDs (i.e., $\mathrm{P}<.0001$ ) of the mean value in controls.

${ }^{\ddagger}$ Beyond \pm 2.5 SDs (i.e., $\mathrm{P}<.01$ ) of the mean value in controls.

trum from the second examination (Fig. 2H) demonstrated a large increase in lactate $(210 \%$ of the initial value) and progressive reduction of NAA (to $49 \%$ of normal).

Static ${ }^{31} \mathbf{P}$ Spectroscopy. Table 2 gives a summary of metabolic parameters extracted from ${ }^{31} \mathrm{P}$ spectra without ST. The level of free intracellular $\mathrm{Mg}^{2+}$ and the cytosolic $\mathrm{pH}$ were within the normal range and did not change significantly upon Cr treatment. In the baseline examination, $\mathrm{PCr}$ was only $80 \%$ of the mean control value, whereas $\mathrm{P}_{\mathrm{i}}$ was elevated at $153 \%$. The estimated free ADP concentration was increased at $191 \%$ with a concomitant elevation in $\mathrm{V} / \mathrm{V}_{\max }$ ( $165 \%$ of the mean control value). The phosphorylation potential was well below the minimum value found in the control group $\left(135 \mathrm{mmol}^{-1}\right)$ and was $38 \%$ of the mean control value. At the end of $\mathrm{Cr}$ treatment, $\mathrm{PCr}$ was increased by $11 \%$ but still did not

Table 2. Cytosolic phosphate metabolite ratios and concentrations measured in the resting gastrocnemius muscle with ${ }^{31} \mathrm{P}$ MRS.

\begin{tabular}{|c|c|c|c|c|}
\hline \multirow[b]{2}{*}{ Variable } & \multirow[b]{2}{*}{ Unit } & \multirow{2}{*}{$\begin{array}{c}\text { Control data } \\
\quad(n=9)\end{array}$} & \multicolumn{2}{|c|}{ MELAS } \\
\hline & & & Baseline & On treatment \\
\hline PCr/ATP & & $3.53 \pm 0.19$ & $2.81^{*}$ & 3.12 \\
\hline$P_{i} / A T P$ & & $0.55 \pm 0.08$ & $0.84^{*}$ & $1.42^{\dagger}$ \\
\hline $\mathrm{P}_{\mathrm{i}} / \mathrm{PCr}$ & & $0.16 \pm 0.02$ & $0.30^{\dagger}$ & $0.45^{\dagger}$ \\
\hline$[\mathrm{PCr}]$ & $\mathrm{mmol} / \mathrm{L}^{-1}$ & $28.9 \pm 1.5$ & $23.0^{*}$ & 25.6 \\
\hline$\left[\mathrm{P}_{\mathrm{i}}\right]$ & $\mathrm{mmol} / \mathrm{L}^{-1}$ & $4.5 \pm 0.7$ & $6.9^{*}$ & $11.7^{\dagger}$ \\
\hline [ADP] & $\mu \mathrm{mol} / \mathrm{L}^{-1}$ & $8.9 \pm 1.3$ & $17.0^{\dagger}$ & $24.8^{\dagger}$ \\
\hline$\left[\mathrm{Mg}^{2+}\right]$ & $\mathrm{mmol} / \mathrm{L}^{-1}$ & $0.9 \pm 0.3$ & 1.6 & 1.5 \\
\hline $\mathrm{pH}$ & & $7.04 \pm 0.02$ & 7.09 & 7.01 \\
\hline PP & $\mathrm{mmol}^{-1}$ & $204 \pm 64$ & 78 & $42^{\star}$ \\
\hline $\mathrm{V} / \mathrm{V}_{\max }$ & & $0.23 \pm 0.03$ & $0.38^{\ddagger}$ & $0.47^{\dagger}$ \\
\hline
\end{tabular}

${ }^{*}$ Beyond \pm 2.5 SDs (i.e., $\mathrm{P}<.01$ ) of the mean value in controls. ${ }^{t}$ Beyond \pm 5 SDs (i.e., $\mathrm{P}<.000001$ ) of the mean value in controls. ${ }^{\ddagger}$ Beyond \pm 4 SDs (i.e., $\left.\mathrm{P}<.0001\right)$ of the mean value in controls. reach the mean control level (89\%). None of the other markers of an abnormal energy metabolism showed a trend towards normalization: $\mathrm{P}_{\mathrm{i}}, \mathrm{ADP}$, and $\mathrm{V} / \mathrm{V}_{\max }$ progressively increased as compared with the mean control values $(260 \%, 279 \%$, and $204 \%$, respectively), whereas the phosphorylation potential further declined $(21 \%)$.

Kinetic Investigations. Saturation-transfer ${ }^{31} \mathrm{P}$ spectra from the patient's calf muscle are presented in Figure 3. Kinetic parameters extracted from fitting the data are given in Table 3 . The rate constants $\mathrm{k}_{+1}$ and $\mathrm{k}_{-1}$ and the fluxes $\mathrm{v}_{\text {for }}$ and $\mathrm{v}_{\mathrm{rev}}$ were somewhat higher than in the control group $(167 \%, 157 \%$, $135 \%$, and $157 \%$, respectively) although only the differences for $\mathrm{k}_{-1}$ and $\mathrm{v}_{\mathrm{rev}}$ were significant. None of the kinetic parameters was significantly affected by $\mathrm{Cr}$ treatment.

\section{DISCUSSION}

Our combined findings from ${ }^{1} \mathrm{H}$ an ${ }^{31} \mathrm{P}$ MRS underline the marked involvement of both brain and skeletal muscle in mitochondrial dysfunction. Results from proton spectroscopy coincide with previous observations in MELAS patients. The generalized increase in lactate may be ascribed to abnormal upregulation of glycolytic activity throughout the brain, including regions that appear normal on MRI. This is consistent with impairment of oxidative phosphorylation due to defective mitochondrial complex I. $\mathrm{N}$-acetyl-L-aspartate is synthesized in brain mitochondria from acetyl-CoA and aspartate and is believed to be present primarily in neurons. The decline in NAA seen in MELAS patients is therefore attributed to neuroaxonal damage. This is further supported by the accompanying decrease of glutamate by an amount similar to that of NAA, which was also ob- 

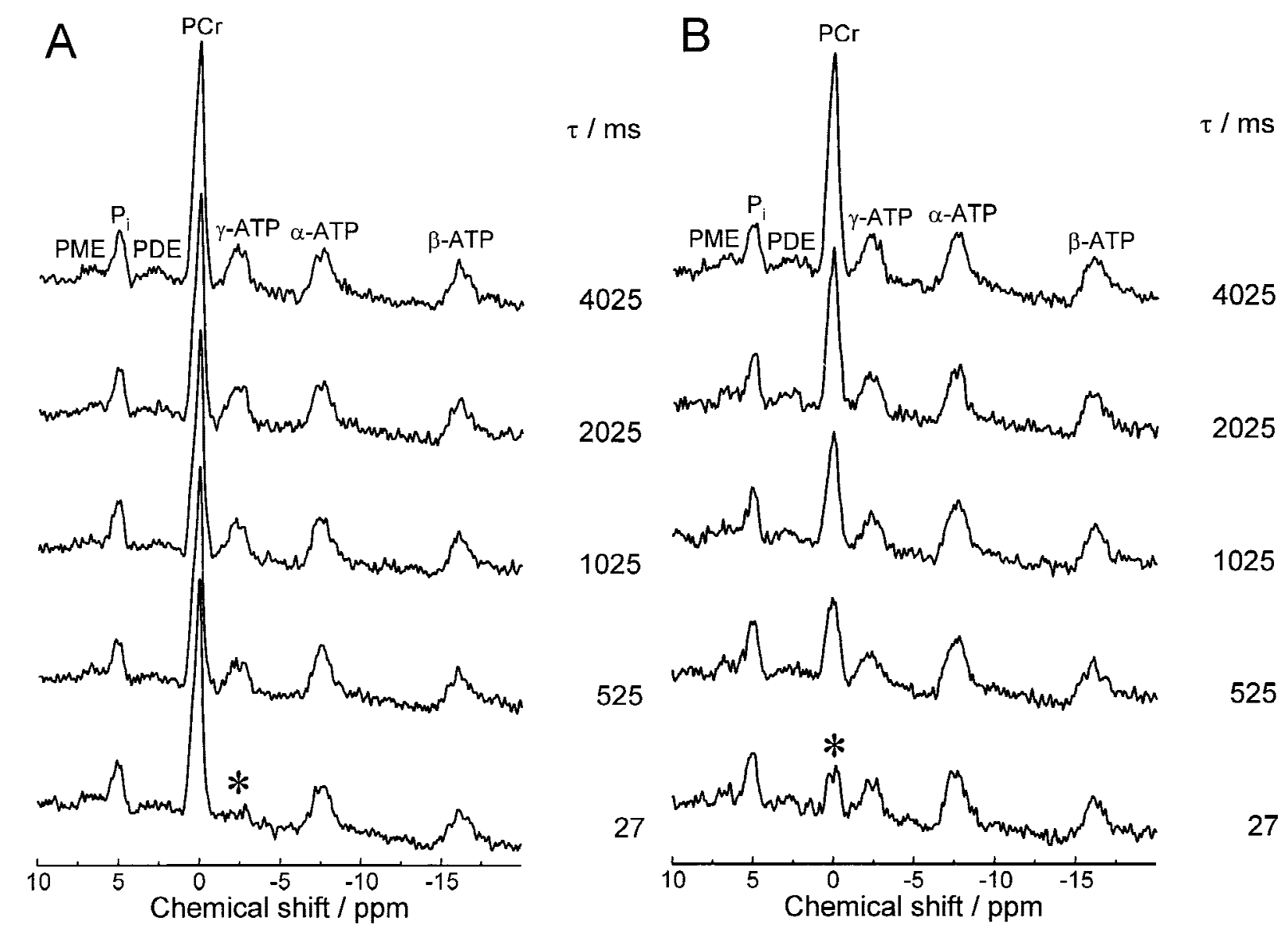

FIGURE 3. Examples of ${ }^{31} \mathrm{P}$ spectra measured during $\mathrm{Cr}$ treatment in the resting gastrocnemius muscle using different mixing times $\tau$ after saturation of (A) $\gamma$-ATP or (B) PCr. The center frequency of the selective saturation pulse is marked by an asterisk. The spectra comprise resonances of $\alpha-(-7.49 \mathrm{ppm}), \beta-(-15.72 \mathrm{ppm})$, and $\gamma$-ATP $(-2.37 \mathrm{ppm}), \mathrm{PCr}(0.00 \mathrm{ppm}), \mathrm{P}_{\mathrm{i}}(4.84 \mathrm{ppm}$, corresponding to a pH of 7.01), phosphomonoesters (PME, $7.09 \mathrm{ppm}$ ), and phosphodiesters (PDE, $2.51 \mathrm{ppm}$ ).

served by Wilichowski and colleagues. ${ }^{35}$ Bates et al. ${ }^{5}$ demonstrated that partial inhibition of single complexes of the respiratory chain can result in decreased NAA production. Impaired mitochondrial function may thus contribute to the observed reduction in NAA without cell death.

Metabolic alterations are considerably pronounced in MRI-detectable lesions. Extensive accumulation of lactate is indicative of a severe energy failure and acute hypoxia during a strokelike episode. ${ }^{35}$ This may, in turn, cause neuronal dysfunction, as evidenced by further reduction in NAA. Similar to previous observations, ${ }^{10}$ transient recovery of NAA and regression of the original lesion at MRI were found in serial investigations (Figs. 2A-2D). This may indicate changes in intracellular NAA as a result of a reversible impairment of mitochondrial function, consistent with the above hypothesis of a decreased NAA production due to defective respiratory chain complex. Comparing the time courses of metabolic changes in both VOIs, the possibility that the transient recovery of NAA and decline of lactate observed in the parieto-occipital operculum were related to Cr treatment may be discounted because the opposite trends were found in occipital cortex. This also indicates that evaluation of a single VOI is insufficient for reliably assessing response to therapy.

The cellular ATP concentration at rest is tightly regulated and was found to be unaffected upon $\mathrm{Cr}$

Table 3. Pseudo-first-order rate constants and fluxes for the CK reaction in the resting gastrocnemius muscle.

\begin{tabular}{|c|c|c|c|c|}
\hline \multirow[b]{2}{*}{ Variable } & \multirow[b]{2}{*}{ Unit } & \multirow{2}{*}{$\begin{array}{l}\text { Control data } \\
\quad(n=3)\end{array}$} & \multicolumn{2}{|c|}{ MELAS } \\
\hline & & & Baseline & On treatment \\
\hline $\mathrm{k}_{+1}$ & $\mathrm{~s}^{-1}$ & $0.39 \pm 0.13$ & 0.65 & 0.53 \\
\hline $\mathrm{k}_{-1}$ & $\mathrm{~s}^{-1}$ & $0.99 \pm 0.09$ & $1.55^{\star}$ & $1.59^{*}$ \\
\hline $\mathrm{k}_{-1} / \mathrm{k}_{+1}$ & & $2.6 \pm 0.6$ & 2.4 & 3.0 \\
\hline$V_{\text {for }}$ & $\mathrm{mmol} / \mathrm{L}^{-1} \mathrm{~S}^{-1}$ & $11.1 \pm 3.1$ & 15.0 & 13.6 \\
\hline$v_{\text {rev }}$ & $\mathrm{mmol} / \mathrm{L}^{-1} \mathrm{~s}^{-1}$ & $8.1 \pm 0.7$ & $12.7^{\star}$ & $13.0^{*}$ \\
\hline
\end{tabular}

${ }^{*}$ Beyond \pm 5 SDs (i.e., $\left.\mathrm{P}<.000001\right)$ of the mean value in controls. 
supplementation. ${ }^{18}$ The assumption of a normal ATP level has also been verified at muscle biopsy in single cases of mitochondrial myopathies. ${ }^{19,31}$ Therefore, using PCr/ATP and $\mathrm{P}_{\mathrm{i}} /$ ATP to calculate $\mathrm{PCr}$ and $\mathrm{P}_{\mathrm{i}}$ concentrations seems justified. Qualitatively and quantitatively, our ${ }^{31} \mathrm{P}$ MRS investigations of the resting gastrocnemius muscle revealed typical features observed in patients with mitochondrial myopathies, ${ }^{2}$ including elevated ADP and $\mathrm{P}_{\mathrm{i}}$ coupled to reduced PCr. Again, these abnormalities reflect the inability of the mitochondria to efficiently utilize oxygen for ATP synthesis. Phosphocreatine and ADP are interrelated via the CK reaction (Eq. 1), which is activated by a rising level of ADP to restore ATP. ${ }^{8}$ Mitochondrial activity determines the phosphorylation potential, which is low, indicating a low energy reserve in the resting muscle. Finally, defective mitochondrial functionality is apparent in an abnormal transfer function for ADP control given by an increased $\mathrm{V} / \mathrm{V}_{\text {max }}$, which points to accelerated ATP production in functioning mitochondria to fulfill the energy demands of the cell., ${ }^{3,12}$ The rise in the resting muscle $\mathrm{PCr}$ by $11 \%$ upon Cr supplementation is at the lower end of increases observed in previous studies of healthy volunteers. ${ }^{20,30,33}$ Besides the moderately increased $\mathrm{PCr}$ availability, Cr treatment did not improve any of the other parameters characterizing muscular energy status at rest (Table 2).

Our kinetic parameters from the control group describing flux through the CK reaction for the direction of ATP synthesis are within the range of previous literature results. ${ }^{14,28}$ The corresponding reverse reaction has not yet been investigated in human muscle. Consistent with findings in animals, ${ }^{6}$ the ratio $\mathrm{k}_{-1} / \mathrm{k}_{+1}$ was approximately 3 . Fluxes $\mathrm{v}_{\text {for }}$ and $\mathrm{v}_{\text {rev }}$ were similar, suggesting near-equilibrium conditions of the CK reaction. It should be noted that kinetic parameters of the resting muscle do not adequately describe conditions of work or recovery from exercise.

An increased concentration of cytosolic ADP, as found in our patient (Table 2), would lead to a higher pseudo-first-order rate constant $\mathrm{k}_{+1}$ consistent with the observed trend (Table 3). A similar effect on $\mathrm{k}_{-1}$ might result from an increased availability of free Cr. However, as the CK reaction is near equilibrium in resting muscle (see above discussion), $\mathrm{PCr}$ resynthesis should not be limited by the CK reaction under out experimental conditions; hence, variations in $\mathrm{Cr}$ per se should not lead to pronounced changes in the CK kinetics. This is in keeping with our observation that Cr treatment did not produce significant effects on the unidirectional CK reaction rates and fluxes.
In summary, there was no clinical improvement from $\mathrm{Cr}$ treatment in our patient. Consistently, except for a slightly elevated intramuscular PCr concentration, no further beneficial effect on various parameters of cellular energy metabolism could be found with static or kinetic investigations using ${ }^{31} \mathrm{P}$ MRS. Cerebral metabolic disturbances and their progress with time observed with ${ }^{1} \mathrm{H}$ MRS were typical for MELAS without demonstrating indications of a beneficial influence from $\mathrm{Cr}$ treatment. In conclusion, follow-up MRS studies are capable of providing objective markers of treatment response in mitochondrial myopathies in vivo without the potential damage inflicted by biopsy. This is particularly important because of the necessarily limited number of patients with such rare disorders that can be studied with any given protocol.

A portion of this work was presented at the 8th scientific meeting of the International Society for Magnetic Resonance in Medicine in April 2000, Denver, Colorado.

\section{REFERENCES}

1. Argov Z, Bank WJ, Maris J, Peterson P, Chance B. Bioenergetic heterogeneity of human mitochondrial myopathies: phosphorus magnetic resonance spectroscopy study. Neurology 1987;37:257-262.

2. Arnold DL, Taylor DJ, Radda GK. Investigation of human mitochondrial myopathies by phosphorus magnetic resonance spectroscopy. Ann Neurol 1985;18:189-195.

3. Barbiroli B, Montagna P, Martinelli P, Lodi R, Iotti S, Cortelli P, Funicello R, Zaniol P. Defective energy metabolism shown by in vivo ${ }^{31} \mathrm{P}$ MR spectroscopy in 28 patients with mitochondrial cytopathies. J Cereb Blood Flow Metab 1993;13:469-474.

4. Barkovich AJ, Good WV, Koch TK, Berg BO. Mitochondrial disorders: analysis of their clinical and imaging characteristics. AJNR Am J Neuroradiol 1993;14:1119-1137.

5. Bates TE, Strangward M, Keelan J, Davey GP, Munro PMG, Clark JB. Inhibition of N-acetylaspartate production: implications for ${ }^{1} \mathrm{H}$ MRS studies in vivo. Neuroreport 1996;7: 1397-1400.

6. Bittl JA, DeLayre J, Ingwall JS. Rate equations for creatine kinase predicts the in vivo reaction velocity: ${ }^{31} \mathrm{P}$ NMR surface coil studies in brain, heart, and skeletal muscle of the living rat. Biochemistry 1987;26:6083-6090.

7. Castillo M, Kwock L, Green C. MELAS syndrome: imaging and proton MR spectroscopy findings. AJNR Am J Neuroradiol 1994;16:233-239.

8. Chance B, Leigh JS Jr, Clark BJ, Maris J, Kent J, Nioka S, Smith D. Control of oxidative metabolism and oxygen delivery in human skeletal muscle: a steady-state analysis of the work/ energy cost transfer function. Proc Natl Acad Sci USA 1985; 82:8384-8388.

9. Clark JM, Marks MP, Adalsteinsson E, Spielman DM, Shuster D, Horoupian D, Albers GW. MELAS: clinical and pathologic correlations with MRI, xenon/CT, and MR spectroscopy. Neurology 1996;46:223-227.

10. De Stefano N, Matthews PM, Arnold DL. Reversible decreases in N-acetylaspartate after acute brain injury. Magn Reson Med 1995;34:721-727.

11. De Stefano N, Matthews PM, Ford B, Genge A, Karpati G, Arnold DL. Short-term dichloroacetate treatment improves indices of cerebral metabolism in patients with mitochondrial disorders. Neurology 1995;45:1193-1198. 
12. Eleff SM, Barker PB, Blackband SJ, Chatham JC, Lutz NM, Johns DR, Bryan RN, Hurko O. Phosphorus magnetic resonance spectroscopy of patients with mitochondrial cytopathies demonstrates decreased levels of brain phosphocreatine. Ann Neurol 1990;27:626-630.

13. Frahm J, Michaelis T, Merboldt KD, Bruhn H, Gyngell ML, Hänicke W. Improvements in localized proton NMR spectroscopy of human brain. Water suppression, short echo times, and $1 \mathrm{ml}$ resolution. J Magn Reson 1990;90:464-473.

14. Goudemant JF, Francaux M, Mottet I, Demeure R, Sibomana $\mathrm{M}$, Sturbois X. ${ }^{31} \mathrm{P}$ NMR saturation transfer study of the creatine kinase reaction in human skeletal muscle at rest and during exercise. Magn Reson Med 1997;37:744-753.

15. Greenhaff PL, Casey A, Short AH, Harris R, Soderlund K, Hultman E. Influence of oral creatine supplementation of muscle torque during repeated bouts of maximal voluntary exercise in man. Clin Sci (Colch) 1993;84:565-571.

16. Hagenfeld L, von Döbeln U, Solders G, Kaijser L. Creatine treatment in MELAS. Muscle Nerve 1994;17:1236-1237.

17. Harris RC, Hultman E, Nordesjo LO. Glycogen, glycolytic intermediates and high-energy phosphates determined in biopsy samples of musculus quadriceps femoris of man at rest. Methods and variance of values. Scand J Clin Lab Invest 1974; 33:109-120.

18. Harris RC, Söderlund K, Hultman E. Elevation of creatine in resting and exercised muscle of normal subjects by creatine supplementation. Clin Sci (Colch) 1992;83:367-374.

19. Hayes DJ, Hilton-Jones D, Arnold DL, Galloway G, Styles P, Duncan J, Radda GK. A mitochondrial encephalomyopathy. A combined ${ }^{31} \mathrm{P}$ magnetic resonance and biochemical investigation. J Neurol Sci 1985;71:105-118.

20. Kreis R, Kamber M, Koster M, Felblinger J, Slotboom J, Hoppeler H, Boesch C. Creatine supplementation-Part II: In vivo magnetic resonance spectroscopy. Med Sci Sports Exerc 1999;31:1770-1777.

21. Kurlemann G, Paetzke I, Möller H, Masur H, Schuierer G, Weglage J, Koch HG. Therapy of complex I deficiency: peripheral neuropathy during dichloroacetate therapy. Eur J Pediatr 1995;154:928-932.

22. Matthews PM, Andermann F, Silver K, Karpati G, Arnold DL. Proton MR spectroscopic characterization of differences in regional brain metabolic abnormalities in mitochondrial encephalomyopathies. Neurology 1993;43:2484-2490.

23. Möller HE, Vermathen P, Rummeny E, Wörtler K, Wuisman P, Rössner A, Wörmann B, Ritter J, Peters PE. In vivo ${ }^{31}$ P NMR spectroscopy of human musculoskeletal tumors as a measure of response to chemotherapy. NMR Biomed 1996;9:347-358.
24. Morris GA, Freeman R. Selective excitation in Fourier transform nuclear magnetic resonance. J Magn Reson 1978;29: 433-462.

25. Pavlakis SG, Kingsley PB, Kaplan GP, Stacpoole PW, O'Shea M, Lustbader D. Magnetic resonance spectroscopy. Use in monitoring MELAS treatment. Arch Neurol 1998;55:849-852.

26. Penn AMW, Lee JWK, Thuillier P, Wagner M, Maclure KM, Menard MR, Hall LD, Kennaway NG. MELAS syndrome with mitochondrial tRNA ${ }^{\text {Leu(UUR) }}$ mutation: correlation of clinical state, nerve conduction, and muscle ${ }^{31} \mathrm{P}$ magnetic resonance spectroscopy during treatment with nicotinamide and riboflavin. Neurology 1992;42:2147-2152.

27. Provencher SW. Estimation of metabolite concentrations from localized in vivo proton NMR spectra. Magn Reson Med 1993;30:672-679.

28. Rees D, Smith MB, Harley J, Radda GK. In vivo functioning of creatine phosphokinase in human forearm muscle, studied by ${ }^{31} \mathrm{P}$ NMR saturation transfer. Magn Reson Med 1989;9:39-52.

29. Shoffner JM, Wallace DC. Oxidative phosphorylation diseases. In: Scriver CR, Beaudet AL, Sly WS, Valle D, editors. The metabolic and molecular bases of inherited disease. New York: McGraw-Hill; 1995. p 1535-1609.

30. Smith SA, Montain SJ, Matott RP, Zientara GP, Jolesz FA, Fielding RA. Effects of creatine supplementation on the energy cost of muscle contraction: a ${ }^{31}$ P-MRS study. J Appl Physiol 1999;87:116-123.

31. Taylor DJ, Kemp GJ, Radda GK. Bioenergetics of skeletal muscle in mitochondrial myopathy. J Neurol Sci 1994;127: 198-206.

32. Taylor DJ, Styles P, Matthews PM, Arnold DA, Gadian DG, Bore P, Radda GK. Energetics of human muscle: exerciseinduced ATP depletion. Magn Reson Med 1986;3:44-54.

33. Vandenberghe $\mathrm{K}$, van Hecke $\mathrm{P}$, van Leemputte M, Vanstapel F, Hespel P. Phosphocreatine resynthesis is not affected by creatine loading. Med Sci Sports Exerc 1999;31:236-242.

34. Wiedermann D, Schneider J, Fromme A, Thorwesten L, Möller HE. Creatine loading and resting skeletal muscle phosphocreatine flux: a saturation-transfer NMR study. MAGMA 2001;13:118-126.

35. Wilichowski E, Pouwels PJW, Frahm J, Hanefeld F. Quantitative proton magnetic resonance spectroscopy of cerebral metabolic disturbances in patients with MELAS. Neuropediatrics 1999;30:256-263.

36. Williams GD, Mosher TJ, Smith MB. Simultaneous determination of intracellular magnesium and $\mathrm{pH}$ from the three ${ }^{31} \mathrm{P}$ NMR chemical shifts of ATP. Anal Biochem 1993;214: $458-467$. 